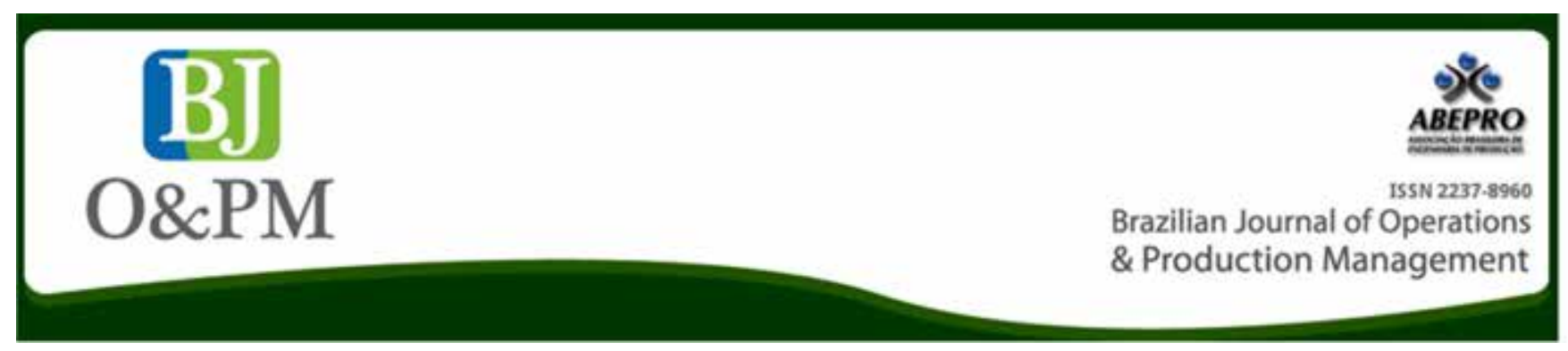

\title{
SMART CONTRACTS: LEGAL FRONTIERS AND INSERTION INTO THE CREATIVE ECONOMY
}

Silvana Santos Gomes silvana.sn.gomes@gmail.com Fluminense Federal University UFF, Niterói, Rio de Janeiro, Brazil.

\begin{abstract}
The ultimate development of a disruptive and innovative contractual form has been imposing new challenges and the need of a proper regulatory framework in the legal field. Smart contracts consist on an internet protocol in which programming language and digital codes are used to input clauses that had already been agreed by the parties and that, upon the fulfillment of a determined condition previously established, shall be automatically self-executed. This new way of creating, transferring and extinguishing patrimonial rights and duties has been playing a major role in the context of the Creative Economy, in which intellectual capital, agility and the automatization of operations constitute fundamental factors. In order to investigate the characteristics and possibilities of adopting smart contracts under the perspective of the Brazilian legal order and its insertion in the Creative Economy, this paper has applied the theoretical and methodological framework of the Economic Analysis of Law so as to pursue the analytical exercise that it is committed to perform.
\end{abstract}

Keywords: Smart Contracts; Creative Economy; Economic Analysis of Law. 


\section{INTRODUCTION}

Post-Modernity and its consequences is, as a matter of consequence and vocation, the framework in which an ever increasing and capillary technological mediation of the social life has been taking place.

Fast and transformative technological advancements have been enabling the emergence of instruments and services that carry with themselves the promise of catalyzing progress and development.

Thus, as enlightened by Alexandre (2000), we no longer live exclusively worried about transforming nature in a utilitarian way, or trying to free humanity from traditional woes and contingencies; however, currently, there must also be a concern about the results - that frequently are not transparent - of technical and economic development.

The contemporary notions of progress do not solely imply on creative processes and on technical improvement, but, instead, they incorporate social, political and economic dimensions that must be able to measure factual consequences and commit to the paradigms of transparency and access to information.

Among the myriad of new tools that have been emerging recently, smart contracts play a major role not only to the development of a series of other technologies, but also to Law and Economics.

In spite of the nomenclature, in reality, smart contracts are internet protocols mainly devoted to negotiating, implementing and performing agreements in a secure, automatized and decentralized manner. In such contracts, clauses, as they are currently known, lose ground to programming language, digital codes and cryptography that, being able to dismiss any intermediary, set forth and self-execute rights and duties in transactions concluded by parties that dot not even have to know each other or have any degree of confidence on one another.

Albeit the Brazilian Civil Code is strongly rooted in the objective good faith principle, whose observance is mandatory during the entire contractual relationship, in practical terms, it is not unusual to verify that the issue of confidence between the parties in executing a certain agreement leads to negotiation processes that are costly, longer and more difficult.

At this point, the Economic Analysis of Law and, particularly, the Transaction Costs Theory conceived by authors who are bound to the New Institutional Economy offer a theoretical framework that is appropriate to understand and to propose solutions to such problematic that inhibits and hinders decision making processes by economic agents.
Transaction costs relate to all the steps of formation and performance of an agreement, besides presenting five determinant factors, namely: (i) bounded rationality; (ii) complexity; (iii) uncertainty; (iv) information asymmetry; and (v) agents' opportunism.

When observing the context in which the most diverse economic transactions have been occurring, it is possible to infer that the Post-Modernity multifaceted character associated with the broad volume of accessible information - but that are not always known by all the parties - have the effect of worsening these costs.

However, traditional business visions and excess of intermediaries are mismatched with the new paradigms brought by the Creative Economy, which is characterized, in essence, by dynamism, primacy of intellectual capital and power of innovation. Hence, Creative Economy involves a transition of traditional models towards a multidisciplinary approach that encompasses economic, financial, cultural, technological and legal elements.

Given this new scenario, all the process that starts with the production of laws and other normative instruments and that ends up in the application of rules, norms and principles by judging authorities is exposed to the new legal challenges that emerge in the society of information and knowledge.

Smart contracts, which constitute one of these challenges, have the potential to unveil new frontiers and possibilities to the Creative Economy. Notwithstanding, without proper regulation, the benefits that would probably be induced may be inhibited by legal uncertainty.

In view of this panorama, this paper intends to contribute to the debate relating to smart contracts, the legal issues that apply to them and their insertion into the Creative Economy under a Law and Economics interdisciplinary standpoint, making use of the theoretical and methodological framework of the Economic Analysis of Law.

The general objective of this paper consists on analyzing the legal frontiers that beacon and constrain smart contracts. Specifically, it has sought to (i) investigate whether smart contracts actually have contractual nature and legal validity; (ii) confront smart contracts with general rule of the Brazilian legal order that may be applicable; (iii) assess how smart contracts may mitigate transaction costs and (iv) identify the way in which the insertion of smart contracts into the Creative Economy occurs.

The interdisciplinary character of the research imposes some reflexes in terms of methodology. In the first place, as explained by Salama (2008), both Economics and Law deal with of problems of coordination, stability and efficiency 
Brazilian Journal of Operations \& Production Management

Volume 15, Número 3, 2018, pp. 376-385

DOI: 10.14488/BJOPM.2018.v15.n3.a4 among society. This similarity in the identification of a problem, including the affinities and complementarities in their analysis, enables the investigation of a given object upon the employment of a range of tools that do not belong exclusively to one area or another, but that incorporates elements of both of them.

The comprehensive vision entailed by the methodological adoption of the Economic Analysis of Law allows the operation of an analytical exercise that extracts conclusions that are more reliable to its research object, since, according to Mello (2006), if legal experts lack the necessary attention to the real effects of normative systems, economists lack the understanding of the internal logic of legal relationships.

Particularly in countries such as Brazil, in which the legal system is rooted in the Civil Law tradition, the prevailing formalist legal culture associates Law to a rational construction of norms by an idealized legislator, resulting, as stated by Kirat \& Saverin, in a legal science without society along with social sciences without Law, what leads to the false idea that Law is a closed normative system and that social regulation is based on reasons other than the legal ones.

With the purpose of addressing the objectives that it is committed to analyzing, this paper has been organized as follows: Section II traces the general characteristics of smart contracts, dealing with questions referring to their nature and legal validity; Section III performs a mapping of the general rules that govern obligations and contracts under the Brazilian Civil Code and that may fall upon smart contracts, indicating relevant points for their regulation as well; in Section IV, the aim is to evaluate how smart contracts can reduce transaction costs; Section $V$ addresses the insertion of smart contracts into the Creative Economy and, finally, in Section $\mathrm{VI}$, some finals remarks are made in light of the content that shall be exposed along this work.

\section{NEW FRONTIERS BETWEEN LAW AND THE INTERNET: SMART CONTRACTS}

Contracts are an essential component of socioeconomic relationships and one of the most relevant legal institutes, mainly to Private Law. In the words of Pereira (2012), the modern world is the world of contracts, and modern life alike, in such a high level that, if we abstracted the contractual phenomenon from the civilization of our time even for a single moment, the consequence would be the stagnation of social life.

The existing dialogue between Law and the Internet is becoming increasingly closer and broader as a plurality of new technological instruments that reverberate in the legal sphere is being disseminated.
The emergence of smart contracts dates back to the enhancement and diversification of internet protocols with the most assorted objectives. In this sense, the Bitcoin protocol and the platform in which it is operated, Blockchain, served as a basis for the development of smart contracts and Ethereum, the most used platform for their hostage.

However, their creation can be identified at a previous moment. In the year of 1997, Nick Szabo published two articles (Formalizing and Securing Relationships on Public Networks and The Idea of Smart Contracts), in which he conceived theories involving the transfer of rights upon the use of algorithms and cryptography.

Specifically in the article The Idea of Smart Contracts, assuming that property has a dynamic and transferable character, Szabo idealized an internet protocol that would help parties to perform contracts in a more efficient way, in order to hinder non-compliance and make contractual breaches more costly, in respect of the pacta sunt servanda principle, which translates into the binding force of contracts.

Notwithstanding, only as of 2008, upon the dissemination of cryptocurrencies and the development of Blochachain, the technical basis that would allow the later creation of Ethereum and the operation of smart contracts were launched. In 2013, programer Vitalik Buterin published a paper describing new functions of Blockchain that could be employed in a digital platform that he had been working on for approximately two years (Lauslahti et al., 2017).

In 2015, Buterin put Ethereum, which is a decentralized platform devoted to creating and operating smart contracts, into operation. Due to safety mechanisms and to the cryptography inscribed in its structuring, Ethereum constitutes a reliable space for parties to transact, as it only executes already established commands - that is, contractual clauses - under the exact terms that they had been programed, preventing third party interferences and halting fraud.

Drawing on a logic that is similar to the one that governs Blockchain, Ethereum presents a high degree of reliability, as it enables the verification of the transactions' origin that are hosted in it upon a public ledger in which users of the system can visualize their metadata.

In addition, each smart contract has a proper address in Ethereum's base that is only accessible by the means of the insertion of the parties' cryptographic key that are involved in the transaction. When the latter is terminated, agents can deactivate the corresponding address and, if they wish to rehabilitate it in a future moment, they will be able to do so, preserving the information that refers to previous transactions. 
Differently from traditional structures, Ethereum is organized in a decentralized and autonomous manner, entailing that its system does not operate based on a central unity or in a group of unities. Thus, it is possible to hinder the servers' administrator to make sudden and inadvertent changes, also because the platform is guided by a consensus protocol, thus meaning that structural changes can only be approved by the agreement of all the users.

Beyond these factors, as a rule, Ethereum is free. No fees are charged to access it or to use the functions that are available at the platform. However, in case the users wish more storage capacity, it is possible to hire additional capacity for reasonable values.

This set of advantages and characteristics has been attracting an increasing number of interested people. According to the data published at Ethereum's website, $13.7 \%$ of users deploy the platform for commercial purposes, while $6.2 \%$ are destined to financial operations, $11.2 \%$ refer to exchange operations and the other usage profiles are divided into categories that are mostly associated with the Creative Economy.

Due to such attributes, one can envision that smart contracts can be employed in four great areas: (i) generally, as accessories to master agreements of deferred or continuous execution; (ii) in the execution of compensatory fines; (iii) in the assessment of the implementation of conditions, terms and charges and (iv) in the sphere of the Creative Economy, as contractual instruments that are particularly appropriate to the practice of Fintechs.

Mainly in relation to items (i), (ii) and (iii) listed above, the reason for adopting smart contracts is coincidental, consisting of their capacity to cause the enforcement of rights and duties inscribed therein with a greater degree of effectiveness.

The importance of this observation is linked to the difficulties that parties, in general, find to correctly comply with their agreements, what represents and central question for every contractual relation, as clarified by Sztajn et al. (2005), to who the problem of enforcing contracts is one of the main elements that defines their design. As parties intend that their agreement leads to effectively driving behavior, they also agree on contractual aspects that play a role of enforcing their fundamental duties.

The last usage area of smart contracts that is dealt by this paper (instrument that is adequate to the practice of Fintechs in the sphere of Creative Economy) shall be addressed with more details in Section V. However, it is opportune to register henceforth that the main factors that justify the said adequacy are the automatization, self-exe- cution and dismissal of third parties to prepare the digital codes that shall implement the commands set forth by the parties.

Besides, the development and the popularization of the use of smart contracts induce the necessity of the establishment of a proper regulation that, simultaneously, grants legal certainty to those whom opt for this kind of contract and inhibits behaviors and transactions that are opportunistic or even illegal.

This latter issue represents a weakness point that requires specific regulatory treatment, as in consideration of the current characteristics of the digital platforms that host smart contracts, since one can verify the existence of mechanisms that enable the performance of transactions with unscrupulous purposes.

Immediately, it can be mentioned the examples of money laundering and illegal remittance of funds overseas. As the bases and platforms where these contracts are operated allow the identification of their users under cryptographed pseudonyms, the anonymity of the parties involved in a transaction can cover up individuals who practice one of the unlawful conducts described above.

In this regard, Juels et al. (2013) had already warned, in their article from 2015, about the misuse that smart contracts may suffer. In the referred work, the authors raise the possibility of using them to hire the services of a murderer. Beyond the criminal aspects involved therein - which shall not be hereby analyzed as they are out of the scope of this paper -, it is clear that, under the perspective of the Brazilian legal order, such contract would be null and void because of the unlawfulness of its purpose.

It is also necessary to consider that smart contracts are instruments of an exclusively digital format, what makes them susceptible to occasional system failures and technical problems that may impair their regular functioning and, thus, cause damage to the parties.

One can perceive that the creation of this contractual type requires us to take a look at Law with dynamic lens, which also means that it must be recognized that Law shall be subject to constant changes and adaptations so that it is able to properly regulate the technological advancements that take place within society.

Mainly when talking about innovation, such necessity is even stronger. Frequently, Law operators come across an equation that requires fine balance in order to be solved: how must Law act to foster the innovative forces that drive society and, at the same time, properly regulate them? 
Brazilian Journal of Operations \& Production Management Volume 15, Número 3, 2018, pp. 376-385

DOI: 10.14488/BJOPM.2018.v15.n3.a4
The answer to this question is far from being reached or outlined, because the multitude of factors that are involved in a social reality increasingly complex and mediated by technological devices substantially change or even shatter structures that were previously known.

\section{SMART CONTRACTS AND THE BRAZILIAN LEGAL ORDER: POSSIBILITIES AND THE NECESSITY OF PROPER REGULATION}

The particularities associated with this contractual instrumentalization that is so disruptive in comparison with the ones that preceded it entail some difficulties in finding a proper regulatory framework. In a first moment, it is even possible to question the necessity of providing the incidence of specific norms to this kind of contract, mainly with a regulatory character.

With a view to its contractual nature, there are no doubts about the application of the ruling set forth in the Civil Code to smart contracts, as a result of the freedom of will and freedom to choose principles. In this regard, it must be highlighted that such legal statute establishes, in its Article 425, that parties can execute atypical contracts provided that the general norms set forth by the concerned Code are duly observed.

One of the main consequences that derive from the application of the general rules contained in the Civil Code to smart contracts refers to the compulsory requirement of complying with their inherent social function, since freedom to contract shall be performed in accordance with the limits of the social function of contracts, as determined by Article 421.

Assuming that contracts are bilateral or multilateral juristic acts, it is necessary that the species hereby analyzed complies with the requirements prescribed by Article 104, namely (i) capable agent; (ii) lawful, possible, determined or determinable purpose; and (iii) prescribed or legally allowed form.

The provision relating to the form that shall be adopted in the execution of a contract points to the validity of smart contracts under the Brazilian legal order. Despite the fact that their structure is considerably different from already existing models, there are no legal prohibitions in this regard.

Similarly, the general rules that address the causes of contracts nullity and voidability also apply to smart contracts. Items IV and V of Article 166 are especially relevant to defending that the atypical form of these contracts cannot give cause to occasional nullity claims.
These provisions state that juristic acts that are not performed under the form prescribed by law or that do not observe any solemnity that is legally deemed as essential for their validity are null. Therefore, there is no legal prohibition to the execution of smart contracts.

In the previous Section of this paper, we have identified four areas in which smart contracts can be employed in order to grant greater effectiveness to transactions, namely, (i) generally, as ancillaries to master agreements of deferred or continuous execution; (ii) in the execution of compensatory fines; (iii) in the assessment of the implementation of conditions, terms and charges; and (iv) in the sphere of the Creative Economy, as contractual instruments that are particularly appropriate to the practice of Fintechs.

In contracts of deferred execution, the fulfillment of the agreed obligation must occur, at one time, in a future moment set forth by the parties, while contracts of continuous execution presuppose that the performance of the obligation takes place in a periodic or successive manner, and for this reason they are also called by the legal doctrine as contracts of successive treatment.

As the purpose of the juristic act is not implemented immediately after its execution or it lasts in the course of time, it is important that creditor has effective ways to secure the fulfillment of the obligation. In the same way, it is also of debtor's interest to be able to prove that he has complied with his duties under the established manner and time so as to settle any inquiries that may lead to default or arrears allegations.

In this context, smart contracts may act as ancillary instruments to a master agreement that contains the dispositions relating to the purpose and way in which it must be fulfilled. In such situation, the former would have the main function of monitoring the compliance of the obligations contained in the latter upon the use of codes that identify in a secure and transparent manner whether the assumed commitments have been duly satisfied.

Consequently, any judicial litigation that would occasionally arise to settle the dispute over contractual fulfillment could be avoided, since parties would be able to unequivocally prove its implementation under the agreed terms.

In case it is verified that debtors are actually in default or arrears, even if it is necessary to adopt judicial measures in order to compel them to perform the obligation or to allow creditors to be compensated for losses and damages that they have suffered, the corresponding process would be better instructed, as parties would bear good means of proof that, on its turn, would support the competent court to fix more rapidly and precisely the compensation quantum. 
The value that is due to creditors for compensation purposes shall follow the rules inscribed in Articles 402 and 405 of the Civil Code. According to these legal provisions, the compensation quantum must embed effective damages and loss of profits, bearing in mind the exceptions set forth by Law and being the interest on arrears counted as from the summons.

Likewise, the verification of the implementation of conditions, terms and charges may also be eased by the use of smart contracts. As per Article 121 of the Brazilian Civil Code, a condition can be deemed as a clause that, deriving exclusively from the will of the parties, subjects the effect of the juristic act to a future and uncertain event.

Conditions are twofold: (i) suspensive, when the commencement of the juristic act's efficiency is subject to a future and uncertain event; and (ii) resolutory, when the occurrence of a determined event entails the termination of the act. Thus, the assessment of the exact moment in which the event stipulated by the parties happens presents direct repercussions in terms of effectiveness.

As a matter of example, one can conceive a purchase agreement in which it is established that creditors shall only acquire a certain imported product when the rate of the dollar is equal or less than BRL 3.41. This is a suspensive condition that may be verified through binding such clause in the smart contract to the official website of the Brazilian Central Bank, which makes daily available the rate of several foreign currencies against the Brazilian real.

Autonomously and automatically, the platform that hosts the smart contract is capable of sending cryptographic messages to the parties signaling that the condition has been fulfilled - in such example, the dollar rate had reached a value that is equal or less than BRL $3.41-$, being also possible that the system proceeds to the subsequent remittance of the value corresponding to the payment that is due to the creditor directly to a bank account that had been linked to the operation.

Within the discussion regarding contracts' efficiency, it must be highlighted that it can be delimited in time. Said delimitation, which is of the essence of the term, occurs when parties fix a moment when the production of effects of a contract commences or terminates.

In light of this definition, one can infer that smart contracts provide ideal mechanisms to verify if the term, whether it has an initial or final character, has been reached and, hence, enable the automatic adoption of measures relating to the beginning or termination of their effects.

On the other hand, under the concept developed by Pereira (2012), charge is a restriction that falls upon the ben- eficiary of a free juristic act, whether imposing an obligation to the favored person for the grantor, third parties or the anonymous community's benefit.

Similarly to the remarks made in regard to the above mentioned institutes, the execution of occasional charges is also subject to inspection and control through the platform in which the respective smart contract is hosted, as long as the insertion of such charge is previously performed into the digital code that shall trigger the corresponding legal effects.

Article 408 of the Civil Code establishes that debtors incur in the compensatory fine by operation of law since, by gross negligence, they do not comply with the obligation or characterize the arrears status. Once again, it is an institute that relates to a hypothesis of default.

As it is possible to extract from Article 409 of the civil legislation, compensatory fine may apply both in the case of a complete or partial default of the obligation (in such case, when the non-compliance relates to a special clause) and of arrears.

The same mechanisms that are used to monitor contracts of deferred or continuous execution, as well as for the verification of the occurrence of conditions, terms and charges may be employed to the ascertainment of circumstances that give cause to the imposition of compensation fines.

Therefore, at the moment of elaboration of the digital codes that shall execute specific commands, it is possible that parties insert, under a binary and mathematically verifiable manner, the criteria that shall serve as a parameter to infer if debtors are on default or arrears and, moreover, to enable the automatic execution of the compensatory fine.

The analysis of the existing difficulties to implement a proper regulatory framework for smart contracts and the Creative Economy shows that it is necessary to take into account what Neuwirth (2011) calls the "holistic paradigm". To the author, the tensions inscribed in these concepts encompass cultural, economic, commercial and technological aspects that point to a legal framework that must be holistic and multidisciplinary.

As stated by Campbell and Collins (2014), under a functional standpoint, one can ascertain that contractual Law promotes and controls social practices that involve the participation in self-regulated transactions. Thus, equivocal comprehensions of these practices create the risk that legal regulation, when required, shall fail in properly sustaining the practice or shall orient its controls in a mistaken direction.

This ascertainment leads to inquiries in regard to the way through which Law must address self-regulated transactions 
Brazilian Journal of Operations \& Production Management Volume 15, Número 3, 2018, pp. 376-385

DOI: 10.14488/BJOPM.2018.v15.n3.a4 and, more specifically, transactions that are mediated by smart contracts, that have in the self-execution and in the automatization two of their main features.

Judging by the state of the art, the general rules of the Brazilian Civil Code that govern obligations and contracts apply to smart contracts, settling the main controversial issues that are associated with elements of validity and nullity.

Nevertheless, the enactment of a regulatory norm that deals with certain aspects involved in the use of smart contracts is convenient. Above all, as defended by Zanitelli (2014), the regulatory framework must be constituted by diverse strategies of intervention, and some of which should not be of a sanctioning nature. This institutional design is in conformity with the so-called "responsive regulation" that is built upon the idea that intervention over a determined sector shall not be solely composed by punishing mechanisms but also by the promotion of incentives that orient the conduct of regulated agents.

Moreover, an occasional regulatory framework must combine stimulus to the beneficial use of smart contracts and repress unlawful practices, subjecting its perpetrators to the sanctions imposed by law. Equally, the consequences and proceedings in case of system failure or technical problems shall be foreseen, with the purpose of curbing opportunistic behavior.

The arrangement entailed by the responsive regulation allows, at one go, the establishment of normative limits to the operation of transactions that employ smart contracts and the removal of obstacles to interactions between socioeconomic agents that have the potential of effectively satisfying their private purposes and generating positive externalities to society, mostly when inscribed in the context of the Creative Economy.

\section{SMART CONTRACTS AND THEIR POTENTIAL TO REDUCE TRANSACTION COSTS}

One of the main advantages relating to the use of smart contracts consists on their potential to significantly reduce transaction costs that, on its turn, are a key category to the Economic Analysis of Law and to the New Institutional Economy.

Initially, some remarks should be made in relation to the origin of these schools of thought. The analysis of the trajectory of the legal and economic thoughts reveals that these thoughts have evolved in an independent way or, according to the Weberian terminology, they have remained incommunicable through their development.
However, in a certain moment of each trajectory, there has been a convergence towards the notion that Law and Economics would be unable to separately explain determined phenomena that they aimed at investigating. This comprehension has led to the emergence of theories that were prone to the adoption of an interdisciplinary approach that fulfilled the methodological boundaries of each of these fields.

In the legal sphere, such paradigm shift is inscribed in a process of disruption during the 1920s, mainly by the Legal Realism School in the United States. In the course of this disruption, two new premises became the fundamental axioms of the American Legal Realism: (i) the practical effect of norms shall be object of consideration in legal research; and (ii) the comprehension of these effects necessarily requires an interdisciplinary approach between Law and the other areas of Social Sciences.

In turn, in the economic field, a similar movement of discontinuity has happened between the Neoclassical and Institutional Schools. Blaug (1985) clarifies that, in methodological terms, institutionalists elaborated three main critics: (i) the opposition to a high degree of abstraction that characterized the Neoclassical Theory; (ii) the recognition of the necessity of integration between Economics with other areas of knowledge; and (iii) a distance from research methods that were deemed as excessively quantitative.

In this context, it is usual to identify two events as the landmarks of the Economic Analysis of Law and, more broadly, of the Law and Economics Movement: the foundation of the Journal of Law and Economics at the University of Chicago in 1959 and the publication of the article "The Problem of Social Cost" by Ronald Coase in 1960.

Coase's academic production constituted a primary reference for the development of both the Economic Analysis of Law and the New Institutional Economy, whose origin is also associated with a reaction against the neoclassical economy and its key postulates.

Mainly as of the article "The Theory of the Firm", from 1937, Coase proposed the concept of transaction costs, which was utterly incorporated into the thought of other authors - especially Douglass North, Oliver Williamson and Guido Calabresi - and was associated with the role played by institutions in their mitigation.

In the definition provided by Fiani (2002), transaction costs are the costs faced by agents every time they access the market. Formally said, transaction costs are the costs of negotiating, writing and securing compliance with a contract. 
To Barzel (1992), the study of contracts makes evident the nature of several transaction costs, which encompass from the costs of finding commercial partners to the costs for preparing contractual clauses. Furthermore, the author highlights the fact that transactions present diverse attributes, being highly costly to foresee, in the contractual instrument, all the events that may affect even the simplest operations.

Given the boundaries of human rationality and the complexity that permeates the environments in which the interactions and exchanges between socioeconomic agents occur, it is expected that parties are unable to anticipate the totality of factors and events that may fall upon certain juristic act.

Additionally, another barrier to the execution of efficient contracts is the informational asymmetry between agents. It is not uncommon that one party possesses information regarding the juristic act's purpose that the other one is not aware of.

In violation of the objective good faith, this situation may give cause to an opportunistic behavior of those who are in a privileged position and, as elucidated by Sztajn et al. (2005), asymmetric information may result in the non-realization of socially desirable relationships (adverse selection) or in unwanted practices (moral hazard), in conflict with the terms that had been negotiated by the parties.

Put otherwise, contracting is a costly activity and, hence, the manner in which it is performed is relevant to lessen costs that present direct effects over the economic output. In parallel, analysis that are grounded on the assumption that people have cognitive boundaries and that Judiciary intervention is not immediate and costless have shown that contracts' design is one of the main foundations of the costs of human interaction and, therefore, of the possibilities of economic development.

Smart contracts are operated in a platform that disposes a public ledger that may be accessed by any user of the system, being the digital commands not subject to third parties interference without consensus over occasional changes. This can expressively reduce informational asymmetry problems and their outcomes, leading ultimately to the mitigation of transaction costs.

\section{THE INSERTION OF SMART CONTRACTS INTO THE CREATIVE ECONOMY}

As stated in the Creative Economy Report, published by the United Nations Conference on Trade and Development from 2010, the concept of Creative Economy is permanently evolving and has been acquiring an ever greater space in the modern thought regarding economic development.
According to this Report, the core of Creative Economy lies on the creative industries, which perform economic activities based on knowledge, intellectual property and, frequently, in intangible assets. This industry network has been creating important precedents, in contrast to other economic sectors that are less dynamic. They interpret and creatively apply knowledge in an innovative way, adopting technologies and new business and cooperation models under an international perspective, aiming to use technology to draw near their customers, as highlighted by Newbigin (2010).

In this same direction, Oliveira et al. point out that Creative Economy can be conceived as a set of economic activities that depend on their symbolic content - included therein creativeness as the most expressive factor for the production of goods and services. This arrangement enables the characterization of the Creative Economy as a discipline that is different from the Cultural Economy, being closely related to economic, cultural and social aspects that interact with technology and intellectual property in the same dimension.

As per the study carried out by the Rio de Janeiro Federation of Industries (FIRJAN, 2016), the participation of the Creative Economy into the Gross Domestic Product (GDP) has been increasing in the entire analyzed period, that is, between 2004 and 2015, year in which the referred participation reached $2.64 \%$, corresponding to roughly BRL 155.6 billion.

Such data gains greater expression when the positive externalities generated by the Creative Economy are analyzed. In relation to this subject, Costa and Souza-Santos (2011) have described that, generally speaking, it is possible to identify the following benefits provided for the Creative Economy: (i) creation of job positions, exportation, promotion and social inclusion, cultural diversity, and human development; (ii) linking economic, cultural and social aspects to technology, intellectual property and touristic purposes; (iii) creation of an economic system based on knowledge and connecting macro and micro economic elements; and (vi) development of innovation through multidisciplinary policies.

Among the factors that foster the Creative Economy, technology represents a cornerstone by constituting the technical apparatus that allows and conditions the performance of activities by all the practice areas of the creative industries. Nonetheless, Fintechs present a more prominent technological vocation and compose a market niche in which the use of smart contracts may have a higher degree of application.

From a conceptual standpoint, Fintechs can be thought as initiatives that combine technology and financial services, offering innovative assets to people and companies, as remarked by the Fintechlab (2016). A common aspect to 
Brazilian Journal of Operations \& Production Management

Volume 15, Número 3, 2018, pp. 376-385

DOI: 10.14488/BJOPM.2018.v15.n3.a4 the companies inscribed in this category is the objective of rendering personalized financial services as an alternative to traditional bank institutions.

Adopting the nature of the service as a distinctive criterion, the practice areas of Fintechs are usually divided into: (i) payment; (ii) financial management; (iii) loan; (iv) investment; (v) funding; (vi) insurance; (vii) debts negotiation; (viii) digital currencies; (ix) exchange and ( $x$ ) multiservices.

The operation of these market segments and, as a consequence, the interactions and transactions between economic agents take place in virtual environments, being any physical contact rare. As they deal with financial services, the existence of contracts that contain provisions on rights and duties of patrimonial nature is of the essence.

It is desirable that Fintechs have at their disposal instruments that fit the agility, automatization and safety requirements that are mandatory to adequately rendering their services. For this reason, it is possible to conclude that, in general, smart contracts are aligned with the demands that arise from the activities inserted into the Creative Economy - with a special focus on Fintechs -, since they provide the features that are fundamental to their efficient development.

\section{CONCLUSIONS}

The dialogue between Law and technology is no longer a futuristic glimpse, but a reality with concrete effects that has been shifting the way in which economic agents transact and contract. The constant changes that derive from this interactive process give rise to the necessity of legal answers to social facts that carry with themselves the mark of innovation.

The increasingly dynamism of economic relationships mainly in the sphere of the Creative

Economy - and the emergence of smart contracts enforce Law operators to adapt themselves to this new manner of agreeing and executing patrimonial rights and duties.

Notwithstanding, the exploration of these new frontiers should not lose sight of the external efficiency of the social function that is inherent to contracts. It is necessary to take a step further so as not to end technological advancements into reductionist perspectives of progress and to actually contribute to a socioeconomic development model that reaches and includes society as a whole.

\section{REFERENCES}

Alexandre, A. F. (2000), A Dinâmica da Sociedade de Risco segundo Anthony Giddens e Ulrich Bech, Geosul, Florianópolis, Vol. 15, No. 30.

Barzel, Y. (1992), Moral Hazard, Monitor Cost and the Choice of Contracts, In: Discussion Papers in Economics, The University of Washington Press, Washington.

Blaug, M. (1985), Economic Theory in Retrospect, Cambridge University Press, Cambridge.

Campbell, D.; Collins, H. (2014), Descobrindo as Dimensões Implícitas dos Contratos. In: Rodriguez, J. R.; Salama, B. M. (Orgs.). Para que serve o Direito Contratual? - Direito, Sociedade e Economia, Direito GV, São Paulo.

Costa, A. D.; Souza-Santos, E. R. (2011), Economia Criativa: novas oportunidades baseadas no capital intelectual, In: Economia \& Tecnologia, Ano 07, Vol. 25.

Federação das Indústrias do Estado do Rio de Janeiro - FIRJAN (2016), Mapeamento da Indústria Criativa no Brasil, In: Diagnósticos e Mapeamentos Setoriais, Publicações Sistema FIRJAN, Rio de Janeiro.

Fiani, R. (2002), Teoria dos Custos de Transação, In: Kupfer, D.; Hasenclever, L. (Orgs.), Economia Industrial: fundamentos teóricos e práticos no Brasil, Campus, Rio de Janeiro.

FintechLab (2016), Report FintechLab 2016, In: Radar Fintech.

Juels, A.; Kosba, A.; Shi, E. (2013), The Ring of Gyges: Using Smart Contracts for Crime, availabe at http://www.arijuels. com/wp-content/uploads/2013/09/Gyges.pdf (Accessed in Jun 03, 2017).

Lauslahti, K.; Mattila, J.; Seppälä, T. (2017), Smart Contracts - How Will Blockchain Technology Affect Contractual Practices?, ETLA Reports, No. 68.

Mello, M. T. L. (2006), Direito e Economia em Weber, Revista Direito GV, Vol. 2, No. 2.

Mundos - doutrina jurídica e pesquisa empírica. Rio de Janeiro: Editora FGV, 2014.

Neuwirth, R. J. (2011), (De-)Regulating the Creative Economy, Creative and Knowledge Society/International Scientific Journal, Vol. 1, No. 1, pp. 44-62.

Newbigin, J. (2010), A Economia Criativa: um guia introdutório, Série Economia Criativa e Cultural, British Council Press, Vol. 1.

Oliveira, J. M; Araújo, B. C.; Silva, L. V. (2013), Panorama da Economia Criativa no Brasil, Instituto de Pesquisa Econômica Aplicada (IPEA), Rio de Janeiro.

Pereira, C. M. S. (2012), Instituições de Direito Civil, Editora Forense, Rio de Janeiro, Vol. 1. 
Salama, B. M. (2008), O que é Pesquisa em Direito e Economia?, Cadernos Direito GV, Vol. 5, No. 2.

Sztajn, R.; Zylbersztajn, D.; Azevedo, P. F. (2005), Economia dos Contratos, in: Sztajn, R.; Zybersztajn, D. (Orgs.), Direito \& Economia - Análise Econômica do Direito e das Organizações, Elsevier, Rio de Janeiro.

United Nations Conference on Trade and Development (UNCTAD) (2010), World Creative Economy Report 2010: the
Brazilian Journal of Operations \& Production Management Volume 15, Número 3, 2018, pp. 376-385 DOI: 10.14488/BJOPM.2018.v15.n3.a4

challenge of assessing the creative economy towards informed policy-making, available at http://www.unctad.org/en/ docs/ditc2010cer_en.pdf (Accessed in June 20, 2017).

Zanitelli, L. M. (2014), Regulação Responsiva e Efeito Solapador das Sanções, In: Porto, A. M.; Sampaio, P. (2014), Direito e Economia em Dois Mundos - doutrina jurídica e pesquisa empírica, FGV, Rio de Janeiro.

Received: 08 Aug 2017

Approved: 01 Aug 2018

DOI: 10.14488/BJOPM.2018.v15.n3.a4

How to cite: Gomes, S. S. (2018), "Smart Contracts: legal frontiers and insertion into the Creative Economy", Brazilian Journal of Operations \& Production Management, Vol. 15, No. 3, pp. 376-385, available from: https://bjopm. emnuvens.com.br/bjopm/article/view/378 (access year month day). 